Original Article

\title{
Reduction in peripheral regulatory $T$ cell population in childhood ocular type myasthenia gravis
}

\author{
Takafumi Nishimura ${ }^{\text {a }}$, Yuji Inaba ${ }^{\text {a,*, }}$, Yozo Nakazawa ${ }^{\text {a }}$, Taku Omata ${ }^{\mathrm{b}}$, \\ Manami Akasaka ${ }^{c}$, Ikuko Shirai ${ }^{\mathrm{d}}$, Motoki Ichikawa ${ }^{\mathrm{e}}$ \\ ${ }^{a}$ Department of Pediatrics, Shinshu University School of Medicine, Matsumoto, Japan \\ ${ }^{b}$ Division of Child Neurology, Chiba Children's Hospital, Chiba, Japan \\ ${ }^{\mathrm{c}}$ Department of Pediatrics, School of Medicine, Iwate Medical University, Morioka, Japan \\ ${ }^{\mathrm{d}}$ Department of Neuropediatrics, Tokyo Metropolitan Neurological Hospital, Tokyo, Japan \\ ${ }^{\text {e }}$ Child and Women's Health Sciences, Graduate School of Medicine, Shinshu University, Matsumoto, Japan
}

Running head: Reduction in Tregs in childhood MG

${ }^{*}$ Correspondence to: Yuji Inaba, MD, PhD

Department of Pediatrics, Shinshu University School of Medicine

Address: 3-1-1 Asahi, Matsumoto 390-8621, Japan

Phone: +81-263-37-2642; Fax: +81-263-37-3089; E-mail: inabay@shinshu-u.ac.jp 


\section{ABSTRACT}

\section{Objective}

Myasthenia gravis (MG) is a T-cell dependent and anti-acetylcholine receptor (AChR) antibody mediated autoimmune disease. Recent studies of adult patients and animal models have shown that regulatory T cells (Tregs) play an important role in the pathogenesis of MG, but little is known about MG in children. This study evaluated the role of peripheral blood Tregs in childhood ocular MG and assessed if Tregs could be an index for estimating immunological status.

\section{Patients and methods}

Clinical data and peripheral lymphocytes were obtained from 13 children with serum AChR antibody-positive ocular type MG and 18 age-matched controls. Committed cells from MG patients were divided into two clinical stages: active $(n=12)$ and remission $(n$ =11). Tregs and Th17 cells were analyzed by flow cytometric analysis based on $\mathrm{CD} 4{ }^{+} \mathrm{CD} 25^{+}$intracellular $\mathrm{FOXP} 3^{+}$and $\mathrm{CD} 4^{+}$intracellular $\mathrm{IL}-17 \mathrm{~A}^{+}$fractions, respectively.

\section{Results}

The percentage of Tregs among peripheral blood $\mathrm{CD}^{+} \mathrm{T}$ cells in active stage, remission stage, and control groups was $3.3 \pm 1.3 \%, 4.8 \pm 1.7 \%$, and $5.0 \pm 0.6 \%$, respectively. The Treg population was significantly lower in the active stage than in the remission stage and controls. Furthermore, Treg percentage was significantly lower during relapse of myasthenia symptoms. We witnessed no remarkable associations between the percentage of Tregs and immune suppressant dosages.

\section{Conclusions}

A significant reduction in the peripheral Treg population is considered to contribute to the pathophysiology of ocular type childhood MG and may be a marker of immunological state in these patients. 


\section{Introduction}

Myasthenia gravis (MG) is an autoimmune disorder generally caused by autoantibodies against the acetylcholine receptors (AChR) of skeletal muscles [1]. Although these autoantibodies are produced by B cells, $\mathrm{CD}^{+}$helper $\mathrm{T}$ (Th) cells specific for $\mathrm{AChR}$ are also required for their production and the development of MG symptoms, for which $\mathrm{T}$ cell clones recognizing immunodominant epitopes of AChR have been described [2].

Naïve $\mathrm{CD}^{+} \mathrm{Th}$ cells can be induced to differentiate towards a regulatory $\mathrm{T}$ cell (Treg) or Th17 phenotype according to the local cytokine milieu [3]. Tregs provide a substantial component of the autoimmune counterbalance, and the thymus plays a role in Treg development and the induction of immunological tolerance [4]. The transcription factor FOXP3, a member of the forkhead family of DNA-binding transcription factors, was found to be highly expressed in $\mathrm{CD} 4^{+}$Tregs that play a critical role in maintaining self-tolerance as well as in regulating immune responses [5]. In particular, $\mathrm{CD} 4^{+} \mathrm{CD} 25^{+}$Tregs have been strongly implicated in immunological tolerance [6]. Defects in Treg function and diminished numbers of $\mathrm{CD}^{+}$Tregs have been described in adult MG cases, but these reports have shown conflicting results [1] [7]. Meanwhile, Th17 cells also appear to be associated with autoimmune diseases, such as multiple sclerosis [8] and rheumatoid arthritis [9], although it is not clear if Th17 cells play a role in the development of childhood MG.

Most pediatric MG patients exhibit ocular type symptoms, including ptosis and/or ophthalmoplegia, without elevated anti-AChR antibodies in the peripheral blood [10] [11] [12]. However, little else is known about the etiology of childhood MG and the causative role of Tregs since adult onset and childhood onset MG are considered to have different pathophysiologies.

In this study, we investigated the populations of $\mathrm{CD} 4^{+} \mathrm{CD} 25^{+}$intracellular $\mathrm{FOXP}^{+}$ Tregs and $\mathrm{CD}^{+}$intracellular IL-17A ${ }^{+}$Th17 cells in children with ocular type MG at various clinical stages and compared them with those of age-matched control subjects. We aimed to clarify the relationship between peripheral Treg populations and clinical symptoms in childhood MG and determine if these populations could represent an index for estimating immunological state and predicting clinical symptoms.

\section{Patients and methods}

\subsection{Patients and controls}

This study included 13 children with ocular type MG (4 males and 9 females) and 18 age-matched control subjects (10 males and 8 females) with epilepsy or developmental retardation who exhibited no inflammatory complications. Subject age was $8.2 \pm 4.7$ 
(mean \pm standard deviation [SD]; range, 2 - 16) years for ocular MG patients and $8.1 \pm$ 5.0 (2 - 16) years for controls. Ocular type MG was diagnosed by neurologists according to standard clinical criteria: 1) the presence of fluctuating in any ocular muscle weakness with fatigability; 2) positive response to an anticholinesterase injection test; and 3) all other muscle strength being normal [11] [13]. Peripheral blood samples were obtained at two clinical stages: 1$)$ the active stage $(n=12)$ that included symptom onset before any treatment $(n=6)$ and the relapse of myasthenia symptoms following remission $(n=6)$; and 2) the remission stage $(n=11)$ that was free of myasthenia symptoms as a result of therapy.

Written informed consent was obtained from the parents of all patients and control subjects before enrollment into the study, which had been approved by the ethics committee of Shinshu University and performed in accordance with the 1964 Declaration of Helsinki and its later amendments. Serum samples were collected from control subjects at the time of clinical requirement.

\subsection{Sample collection and storage}

Peripheral venous blood samples were obtained before and after treatment at various time points for each patient when blood examinations were clinically required. Peripheral blood mononuclear cells (PBMNCs) were immediately isolated from heparinized venous blood by density gradient centrifugation using Ficoll-Paque (GE Healthcare, NJ, USA). The acquired PBMNCs were washed twice with $\mathrm{pH} 7.2$ phosphate-buffered saline (PBS) and stored in a CELLBANKER (Zenoaq, Fukushima, Japan) at $-80{ }^{\circ} \mathrm{C}$ until analysis.

\subsection{Staining of Tregs}

For Treg staining assays, cryopreserved PBMNCs were thawed and washed three times with PBS. Staining for Tregs was performed according to the manufacturer's instructions. Briefly, $1 \times 10^{6}$ cells were incubated on ice for 20 min after staining with a 10- $\mu \mathrm{L}$ cocktail of PerCP-Cy5.5-conjugated CD4 (Becton Dickinson [BD] Biosciences, San Jose, USA) and phycoerythrin (PE)-conjugated CD25 (anti-IL-2R) (BD Biosciences, San Jose, USA). The cells were washed twice with PBS and then FOXP3 fix/perm solution (BioLegend, San Diego, CA) was added to each tube. The re-suspended cells were incubated in darkness for 20 minutes at room temperature. After washing twice with permeabilization buffer, the cells were stained with $5 \mu \mathrm{L}$ Alexa Fluor 488-conjugated anti-human FOXP3 (BioLegend, San Diego, USA) or Alexa Fluor 488-conjugated mouse IgG1 $\kappa$ isotype control antibody (BioLegend, San Diego, USA) as a negative control and incubated in darkness for 30 minutes [14]. 


\subsection{Staining of intracellular IL-17A}

To quantify the Th17 cell population in peripheral blood, staining of intracellular IL-17A in stimulated PBMNCs was performed following the manufacturer's instructions. Cryopreserved PBMNCs were thawed and cultured in 6-well plates at $1 \times 10^{6}$ cells/ml per well in RPMI 1640 medium with $200 \mathrm{mM}$ Glutamine and $10 \%$ heat inactivated fetal calf serum (Gibco, Grand Island, USA). The cells ware cultured with 5 $\mu \mathrm{g} / \mu \mathrm{L}$ phorbol 12-myristate-13-acetate (PMA) (SIGMA, St. Louis, USA), $1 \mu \mathrm{g} / \mu \mathrm{L}$ ionomycin (SIGMA, St. Louis, USA), and $0.8 \mu \mathrm{L} / \mathrm{mL}$ BD GolgiStop for 4 hours $\left(37^{\circ} \mathrm{C}\right.$; $5 \% \mathrm{CO} 2$ ). The stimulated cells were transferred to tubes and washed once with PBS. Before surface staining, the cells were fixed and permeabilized according to the manufacturer's instructions (BD Cytofix/Cytoperm Fixation/Permeabilization Solution Kit with BD GolgiStop), then stained with PE antihuman CD4 (BioLegend, San Diego, USA) and Alexa Fluor 488-conjugated anti-human IL-17A (BioLegend, San Diego, USA) or Alexa Fluor 488-conjugated mouse IgG1 $\kappa$ isotype control antibody (BioLegend, San Diego, USA) as a negative control at $4{ }^{\circ} \mathrm{C}$ for 30 minutes [15].

\subsection{Flow cytometric analysis}

Flow cytometric analysis was performed using a FACSCalibur (BD, San Jose, USA). For three-color analysis of Tregs, the cells were stained with CD4-PerCP-Cy5.5, CD25-PE, and Alexa Fluor 488-conjugated anti-human FOXP3. For two-color analysis of Th17 cells, the cells were stained with CD4-PE and Alexa Fluor 488-conjugated anti-human IL-17A [16]. During analysis, a gate was set around the viable lymphocytes based on their forward scatter/side scatter profile to exclude monocyte and granulocyte populations. Fluorescence signals were collected in log mode. A total of 50,000 events were counted for each sample and the data were analyzed using CellQuest software (BD, San Jose, USA) (Fig. 1).

\subsection{Statistical analysis}

The correlation between age and the percentage of Treg/CD4 ${ }^{+} \mathrm{T}$ cells in control subjects was assessed by regression analysis. For comparisons of the mean percentages of Treg/CD4 ${ }^{+} \mathrm{T}$ cells and $\mathrm{Th} 17 / \mathrm{CD}^{+} \mathrm{T}$ cells at various stages in $\mathrm{MG}$ patients and controls, the data were first analyzed by one-way ANOVA. Statistics were carried out using Bonferroni/Dunn multiple comparison tests. Changes in the percentage of Treg/CD4 ${ }^{+} \mathrm{T}$ cells before and after relapse were analyzed with the paired t-test. The relationships between Treg/CD4 ${ }^{+} \mathrm{T}$ cells and Th17/CD4 ${ }^{+}$cells, AChR antibody level, corticosteroid dosage, and serum concentration of tacrolimus were analyzed using 
Pearson's correlation coefficient test. When committed cells were collected multiple times during the same clinical stage in a given patient, data analysis was performed on the mean value of each sample. All statistical analyses were conducted using PASW statistics, Version 18 (SPSS, Inc., Chicago, USA). A $P$-value of less than 0.05 was considered to be statistically significant. All data were expressed as the mean $\pm \mathrm{SD}$.

\section{Results}

\subsection{Clinical data and Treg/CD4 ${ }^{+}$cells}

The clinical data of active (including onset and relapse) and remission stages in ocular MG patients and of age-matched control subjects are listed in Table 1. Serum anti-AChR antibody levels were elevated in both patient groups. Three patients achieved remission using anti-cholinesterase agents without prednisolone (PSL). Of the 8 remission patients who had received PSL, 3 patients required additional immune suppressants, such as tacrolimus ( 2 patients) or azathioprine (1 patient). No patient required thymectomy. The number of $\mathrm{CD} 4^{+}$lymphocytes in ocular MG patients was significantly lower than that in controls $(P<0.01)$.

Figure 2 presents the relationship between age and the percentage of Tregs among peripheral blood $\mathrm{CD} 4^{+} \mathrm{T}$ cells in control subjects. There was no significant correlation between these parameters in regression analysis $\left(\mathrm{R}^{2}=0.036, P=0.45\right)$. The mean value of Treg/CD $4^{+} \mathrm{T}$ cells was $5.0 \pm 0.6 \%$, which was comparable to that of a cohort of adult healthy donors $(5.1 \pm 0.8 \%, \mathrm{n}=16)$.

The percentage of Tregs among peripheral blood $\mathrm{CD}^{+} \mathrm{T}$ cells in the active and remission stages of ocular type $\mathrm{MG}$ and in control subjects was $3.3 \pm 1.3 \%, 4.8 \pm 1.7 \%$, and $5.0 \pm 0.6 \%$, respectively (Fig. 3). Treg percentage in the active stage was significantly lower than those in the remission stage $(P=0.033)$ and in controls $(P<$ 0.001). There was no significant difference in Treg percentage between remission and control groups.

To evaluate the influence of immune suppressive treatment on Treg percentage among peripheral blood $\mathrm{CD}^{+} \mathrm{T}$ cells, we performed regression analysis of the percentage of Tregs in the remission stage and dosage of PSL, tacrolimus or serum level of anti-AChR antibody. No significant correlations were found for PSL $\left(\mathrm{R}^{2}=0.0046, P\right.$ $=0.56$; data not shown), serum concentration of tacrolimus $\left(\mathrm{R}^{2}=0.077, P=0.17\right)$, or serum anti-AChR antibody level $\left(\mathrm{R}^{2}=0.0041, P=0.45\right)$.

\subsection{Representative clinical courses}

\section{Case 1 (Fig. 4a)}

A 13-year-old boy with no past or family history of autoimmune disorders began 
exhibiting intermittent ptosis of his right eyelid with diurnal fluctuation. He had no extraocular symptoms or thymic lesion. He was diagnosed as having ocular type $\mathrm{MG}$ based on positive serum anti-AChR antibody $(0.7 \mathrm{nmol} / \mathrm{L})$ and an intravenous edrophonium test. He was initially treated with pyridostigmine $(3.5 \mathrm{mg} / \mathrm{kg})$, which led to the prompt disappearance of the ptosis (first remission). One month afterwards, his ptosis relapsed. He began treatment with oral PSL and symptoms disappeared within 2 months. A second relapse of MG symptoms was observed five months after the second remission. The addition of tacrolimus improved his condition. As serum AChR antibody was below detection level after the second remission, PSL could be tapered without incident. The percentage of Treg/CD4 ${ }^{+} \mathrm{T}$ cells was $2.6 \%$ at disease onset, which was $-4.0 \mathrm{SD}$ of age-matched healthy controls. However, this percentage became comparable with that of controls during the first remission period. Treg/CD4 ${ }^{+} \mathrm{T}$ cell ratio was seen to vary according to clinical status as follows: first relapse, $1.1 \%$; second remission, $5.3 \%$; and second relapse, $2.0 \%$. The ratio was a near-normal $4.2 \%$ during the third remission period with tacrolimus administration.

\section{Case 2 (Fig. 4b)}

A 2-year-old girl with no family or past history of autoimmune diseases exhibited intermittent bilateral ptosis with diurnal fluctuation and was diagnosed as having ocular type MG based on an intravenous edrophonium test. Both anti-AChR antibody and anti-MuSK antibody were negative at symptom onset and no thymic abnormalities were detected by MRI or SPECT. Her ptosis disappeared following treatment with distigmine $(0.15 \mathrm{mg} / \mathrm{kg})$ and oral PSL. Although her first remission period lasted for more than two years, ptosis and diplopia recurred after decreasing the dose of PSL at 6 years of age. Anti-AChR antibody was detectable at the time of the relapse. An increased dosage of oral PSL led to a second remission. Although the percentage of Tregs among peripheral blood $\mathrm{CD}^{+} \mathrm{T}$ cells during the first remission period was not low (5.2\%), it had dropped to $1.8 \%$ at relapse but then increased to $6.4 \%$ during the second remission.

\subsection{Ratio of Treg/CD4 cells at relapse in 6 cases}

A total of 6 cases experienced relapse of ocular myasthenia symptoms in our cohort. In Figure 4c, PBMNC samples obtained before, during, and after relapse show the time course changes in Treg percentage among peripheral blood $\mathrm{CD}^{+} \mathrm{T}$ cells. The percentage of Treg/CD4 ${ }^{+} \mathrm{T}$ cells had decreased significantly at relapse in most patients $(P=0.003)$, but then increased as a similar degree by more intensive treatment for $1-5$ months resulted in remission $(P=0.009)$. 


\subsection{Th17 cells in MG patients}

To evaluate the role of Th17 cells in the pathophysiology of MG, the percentage of $\mathrm{CD} 4{ }^{+} \mathrm{IL}-17 \mathrm{~A}^{+}$cells among $\mathrm{CD} 4^{+} \mathrm{T}$ cells in stimulated PBMNCs at each clinical MG stage and in controls was evaluated by flow cytometric analysis. The mean percentages in the active stage, remission stage, and in controls were $0.26 \pm 0.21 \%(\mathrm{n}=12), 0.22 \pm$ $1.3 \%(\mathrm{n}=10)$, and $0.21 \pm 0.13 \%(\mathrm{n}=16)$, respectively (Fig. 5). There were no significant differences among the groups, nor were there any significant correlations between the Th17 population and peripheral Tregs $\left(\mathrm{R}^{2}=0.0064, P=0.57\right)$ or level of anti-AChR antibodies $\left(\mathrm{R}^{2}=0.044, P=0.12\right)$. The mean fluorescence intensity of IL-17A in $\mathrm{CD}^{+}$cells was also similar among the groups (data not shown).

\section{Discussion}

Tregs are considered to play an important role in the development of MG, a CD4 T-cell dependent autoimmune disease mediated by anti-AChR antibodies. Although recent studies have paid great attention to Tregs, several earlier reports on peripheral blood Tregs in MG patients have been conflicting. One possible cause for this is the selection of different Treg-associated molecules in defining the cell line [14] [17]; former studies used flow cytometric analysis to measure the number of Tregs as represented by $\mathrm{CD} 4^{+} \mathrm{CD} 25^{+} \mathrm{T}$ cells [18] or CD4 cells with high expression of CD25 [19-24], whereas recent reports on adult MG and experimental autoimmune MG (EAMG) identified Tregs as $\mathrm{CD}^{+} \mathrm{CD} 25^{+} \mathrm{FOXP} 3^{+}[14,25,26]$ As a member of the forkhead family of DNA-binding transcription factors, FOXP3 is highly expressed in $\mathrm{CD}^{+}$Tregs and is considered to play a critical role in maintaining self-tolerance and regulating immune responses [5]. Aricha $\mathrm{R}$ et al. reported that although the number of $\mathrm{CD} 4{ }^{+} \mathrm{CD} 25^{+}$cells in the spleen of EAMG rats was not elevated, the ratio of $\mathrm{CD}_{25}{ }^{+} \mathrm{FOXP}^{+}$cells among $\mathrm{CD} 4^{+}$cells was significantly increased by treatment [21]. $\mathrm{Xu} \mathrm{W}-\mathrm{H}$ et al. uncovered significantly smaller peripheral Treg populations in adult MG patients but increased Treg population sizes following immune suppression therapy [14].

In contrast to adult onset MG, little is known about the immunological mechanism responsible for childhood onset $\mathrm{MG}$, which is considered to be distinct from its adult counterpart [11] [12]. Shinomiya et al. reported on specific HLA subtypes associated with childhood MG in Japan [10]. Sakuma et al. demonstrated that the percentage of $\mathrm{CD} 4^{+} \mathrm{CD} 25^{+}$Tregs was decreased in a child with $\mathrm{MG}$ after successful treatment with PSL, but they did not analyze the $\mathrm{CD} 4^{+} \mathrm{CD} 25^{+} \mathrm{FOXP} 3^{+}$population [24]. In the present study, we analyzed the $\mathrm{CD} 4^{+} \mathrm{CD} 25^{+} \mathrm{FOXP} 3^{+}$subset in PBMNCs obtained from children with ocular type MG and from age-matched control subjects. Similarly to another study 
[27], we observed that the percentage of Tregs among peripheral blood $\mathrm{CD} 4{ }^{+} \mathrm{T}$ cells did not depend on age and that values were comparable between children and adults. However, ours is the first report to describe that the percentage of Tregs in the active stage of pediatric ocular MG is significantly lower than that of controls but is restored during remission following immunosuppressive therapy. These results are consistent with those found in adult patients [14] [20] [21] [28].

This study demonstrated the time course changes in Treg percentage among peripheral blood $\mathrm{CD} 4{ }^{+} \mathrm{T}$ cells before and after relapse of myasthenia symptoms. There was a marked decrease in Treg percentage at the time of relapse in most cases, which later returned to control levels after increased immunosuppressive treatment. To our knowledge, there are only a few reports describing the pathophysiological mechanisms of relapse in MG, such as the TCR V $\beta$ expression repertoire and TCR spectratypes [29] and the presence of both intracellular adhesion molecule-1 and lymphoid function-associated antigen-1 in thymic tissue [30]. It is also well known that serum titer of autoantibodies, such as anti-AChR, is not reflected in myasthenia symptoms [31]. To date, there have been no studies on Tregs or the function of T cells in the relapse phase of childhood myasthenia symptoms; ours may be the first to show a marked decrease in Treg percentage during the relapse phase of ocular MG that could also be a useful marker to predict and evaluate disease recurrences.

Correlations between therapeutic agents and Treg percentage among peripheral blood $\mathrm{CD} 4{ }^{+} \mathrm{T}$ cells were assessed to determine whether the changes in Treg populations were directly influenced by the therapeutic agents. Some reports have shown a significant negative correlation between changes in Treg populations and PSL dose [28] and that corticosteroids promoted the development of Tregs via inhibition of dendritic cell maturation [20]. Although tacrolimus was found to have both promoting [32] and inhibitory effects on the Treg population [33] [34], another study showed that tacrolimus did not alter the expression of FOXP3 in T cells [35]. We observed no correlations between the percentage of Tregs and the dosage of corticosteroids or serum concentration of tacrolimus during the remission phase. Thus, it is possible that Treg ratio is not dependent on immunosuppressive therapy agents, but rather indicates the immunological status of childhood ocular MG.

Recent studies have demonstrated that the ratio of Th17 cells changes most notably with disease progression accompanied by IL-17 up regulation [36]. The involvement of autoreactive Th17 cells in the development of MG has been established in animal models of autoimmune MG [7]. Th17 cells affect the production of autoantibodies through their influence on the Th1/Th2 cytokine balance in PBMNCs of adult MG patients [28]. However, it is not clear whether Th17 cells play a critical role in human 
MG pathophysiology. In this study, we analyzed the percentage of $\mathrm{CD}^{+} \mathrm{IL}_{-17 \mathrm{~A}^{+} \text {cells }}$ among $\mathrm{CD}^{+} \mathrm{T}$ cells in stimulated PBMNCs from childhood ocular MG patients but found no significant differences between patient groups and control subjects. There was also no remarkable correlation between the percentages of Tregs and Th17 cells, suggesting that peripheral Tregs more strongly influence the development of childhood ocular MG symptoms. We also witnessed no significant correlation between Treg percentage and serum anti-AChR antibody level. There have been two clinical studies on the relationship between anti-AChR antibody and the Th17 population: one showed a significant positive correlation [37] while the other showed none [28]. Further study is required to clarify the role of Th17 cells in MG patients.

In conclusion, this is the first report to demonstrate that the percentage of Tregs among peripheral blood $\mathrm{CD}^{+} \mathrm{T}$ cells is significantly lower in the active stage of childhood onset ocular type MG but then returns to levels that are comparable with those of control subjects during remission. As the percentage of Tregs was remarkably decreased in the relapse phase, Tregs may be considered to reflect disease activity in childhood ocular MG as a representative clinical biomarker. On the other hand, peripheral blood Th17 cells appear to be unrelated with disease activity. Further study on the pathophysiological role and possible predictive ability of Tregs may provide important insights into childhood ocular MG.

\section{Acknowledgements}

The authors deeply appreciate the technical assistance in flow cytometric analysis from Mr. Susumu Ito (Division of Instrumental Analysis of the Research Center for Human and Environmental Sciences, Shinshu University). 


\section{References}

[1] Vincent A, Palace J, Hilton-Jones D. Myasthenia gravis. Lancet 2001;357:2122-8.

[2] Sommer N, Harcourt GC, Willcox N, Beeson D, Newsom-Davis J. Acetylcholine receptor-reactive T lymphocytes from healthy subjects and myasthenia gravis patients. Neurology 1991;41:1270-6.

[3] Bettelli E, Carrier Y, Gao W, Korn T, Strom TB, Oukka M, et al. Reciprocal developmental pathways for the generation of pathogenic effector TH17 and regulatory T cells. Nature 2006;441:235-8.

[4] Sakaguchi S, Sakaguchi N, Asano M, Itoh M, Toda M. Immunologic self-tolerance maintained by activated T cells expressing IL-2 receptor alpha-chains (CD25). Breakdown of a single mechanism of self-tolerance causes various autoimmune diseases. J Immunol 1995;155:1151-64.

[5] Sakaguchi S. Naturally arising CD4+ regulatory t cells for immunologic self-tolerance and negative control of immune responses. A Annu Rev Immunol 2004;22:531-62.

[6] Bonelli M, Savitskaya A, von Dalwigk K, Steiner CW, Aletaha D, Smolen JS, et al. Quantitative and qualitative deficiencies of regulatory $\mathrm{T}$ cells in patients with systemic lupus erythematosus (SLE). Int Immunol 2008;20:861-8.

[7] Bai Y, Liu R, Huang D, La Cava A, Tang YY, Iwakura Y, et al. CCL2 recruitment of IL-6-producing $\mathrm{CD} 11 \mathrm{~b}+$ monocytes to the draining lymph nodes during the initiation of Th17-dependent B cell-mediated autoimmunity. Eur J Immunol 2008;38:1877-88.

[8] Kebir H, Kreymborg K, Ifergan I, Dodelet-Devillers A, Cayrol R, Bernard M, et al. Human TH17 lymphocytes promote blood-brain barrier disruption and central nervous system inflammation. Nat Med 2007; $13: 1173-5$.

[9] Kotake S, Udagawa N, Takahashi N, Matsuzaki K, Itoh K, Ishiyama S, et al. IL-17 in synovial fluids from patients with rheumatoid arthritis is a potent stimulator of osteoclastogenesis. J Clin Invest 1999;103:1345-52.

[10] Shinomiya N, Nomura Y, Segawa M. A variant of childhood-onset myasthenia gravis: HLA typing and clinical characteristics in Japan. Clin Immunol 2004;110:154-8.

[11] Chiang LM, Darras BT, Kang PB. Juvenile myasthenia gravis. Muscle Nerve 2009;39:423-31.

[12] Finnis MF, Jayawant S. Juvenile myasthenia gravis: a paediatric perspective. Autoimmune Dis 2011;2011:404101.

[13] Jaretzki A, 3rd, Barohn RJ, Ernstoff RM, Kaminski HJ, Keesey JC, Penn AS, et al. Myasthenia gravis: recommendations for clinical research standards. Task Force of the Medical Scientific Advisory Board of the Myasthenia Gravis Foundation of America. Neurology 2000;55:16-23.

[14] Xu WH, Zhang AM, Ren MS, Zhang XD, Wang F, Xu XC, et al. Changes of Treg-associated molecules on CD4+CD25 + Treg cells in myasthenia gravis and effects of immunosuppressants. J Clin Immunol 2012;32:975-83.

[15] Shi YH, Shi GC, Wan HY, Jiang LH, Ai XY, Zhu HX, et al. Coexistence of Th1/Th2 and Th17/Treg imbalances in patients with allergic asthma. Chin Med J (Engl) 2011;124:1951-6.

[16] Jung T, Schauer U, Heusser C, Neumann C, Rieger C. Detection of intracellular cytokines by flow 
cytometry. J Immunol Methods 1993;159:197-207.

[17] Thiruppathi M, Rowin J, Ganesh B, Sheng JR, Prabhakar BS, Meriggioli MN. Impaired regulatory function in circulating CD4(+)CD25(high)CD127(low/-) T cells in patients with myasthenia gravis. Clin Immunol 2012;145:209-23.

[18] Luther C, Poeschel S, Varga M, Melms A, Tolosa E. Decreased frequency of intrathymic regulatory T cells in patients with myasthenia-associated thymoma. J Neuroimmunol 2005;164:124-8.

[19] Battaglia A, Di Schino C, Fattorossi A, Scambia G, Evoli A. Circulating CD4+CD25+ T regulatory and natural killer $\mathrm{T}$ cells in patients with myasthenia gravis: a flow cytometry study. J Biol Regul Homeost Agents 2005;19:54-62.

[20] Fattorossi A, Battaglia A, Buzzonetti A, Ciaraffa F, Scambia G, Evoli A. Circulating and thymic CD4 CD25 T regulatory cells in myasthenia gravis: effect of immunosuppressive treatment. Immunology 2005;116:134-41.

[21] Aricha R, Feferman T, Fuchs S, Souroujon MC. Ex vivo generated regulatory T cells modulate experimental autoimmune myasthenia gravis. J Immunol 2008;180:2132-9.

[22] Luther C, Adamopoulou E, Stoeckle C, Brucklacher-Waldert V, Rosenkranz D, Stoltze L, et al. Prednisolone treatment induces tolerogenic dendritic cells and a regulatory milieu in myasthenia gravis patients. J Immunol 2009; 183:841-8.

[23] Matsui N, Nakane S, Saito F, Ohigashi I, Nakagawa Y, Kurobe H, et al. Undiminished regulatory T cells in the thymus of patients with myasthenia gravis. Neurology 2010;74:816-20.

[24] Sakuma H, Katayama A, Saito Y, Komaki H, Nakagawa E, Sugai K, et al. CD4+ CD25(high) regulatory T cell in childhood ocular myasthenia gravis. Brain Dev 2011;33:442-4.

[25] Balandina A, Lecart S, Dartevelle P, Saoudi A, Berrih-Aknin S. Functional defect of regulatory CD4(+)CD25+ $\mathrm{T}$ cells in the thymus of patients with autoimmune myasthenia gravis. Blood 2005;105:735-41.

[26] Liu R, Zhou Q, La Cava A, Campagnolo DI, Van Kaer L, Shi FD. Expansion of regulatory T cells via IL-2/anti-IL-2 mAb complexes suppresses experimental myasthenia. Eur J Immunol 2010;40:1577-89.

[27] Grindebacke H, Stenstad H, Quiding-Jarbrink M, Waldenstrom J, Adlerberth I, Wold AE, et al. Dynamic development of homing receptor expression and memory cell differentiation of infant CD4+CD25high regulatory T cells. J Immunol 2009;183:4360-70.

[28] Masuda M, Matsumoto M, Tanaka S, Nakajima K, Yamada N, Ido N, et al. Clinical implication of peripheral CD4+CD25+ regulatory T cells and Th17 cells in myasthenia gravis patients. J Neuroimmunol 2010;225:123-31.

[29] Dokai H, Nomura Y, Fujikawa Y, Nihei K, Segawa M, Shinomiya N. A study of the factors inducing the development of childhood-onset myasthenia gravis using CDR3 spectratyping analysis of the TCR repertoire. J Neuroimmunol 2007;187:192-200.

[30] Yahikozawa H, Koh CS, Inoue A, Hashimoto T, Yanagisawa N. A patient with a relapse of 
myasthenia gravis after a 13-year remission following successful treatment by mediastinal irradiation and corticosteroid therapy (in Japanese). No to shinkei = Brain and nerve (Tokyo) 1995;47:585-8.

[31] Roses AD, Olanow CW, McAdams MW, Lane RJ. No direct correlation between serum antiacetylcholine receptor antibody levels and clinical state of individual patients with myasthenia gravis. Neurology 1981;31:220-4.

[32] Kogina K, Shoda H, Yamaguchi Y, Tsuno NH, Takahashi K, Fujio K, et al. Tacrolimus differentially regulates the proliferation of conventional and regulatory CD4(+) T cells. Mol Cells 2009;28:125-30.

[33] Miroux C, Morales O, Ghazal K, Othman SB, de Launoit Y, Pancre V, et al. In vitro effects of cyclosporine A and tacrolimus on regulatory T-cell proliferation and function. Transplantation 2012;94:123-31.

[34] Shen Z, Song Q, Chen L, Zhong B, Tang S, Hao F. Bidirectional immunoregulation of calcineurin inhibitor tacrolimus on FOXP3 transcription? Med Hypotheses 2011;76:178-80.

[35] Minami N, Fujiki N, Doi S, Shima K, Niino M, Kikuchi S, et al. Five-year follow-up with low-dose tacrolimus in patients with myasthenia gravis. J J Neurol Sci 2011;300:59-62.

[36] Mu L, Sun B, Kong Q, Wang J, Wang G, Zhang S, et al. Disequilibrium of T helper type 1, 2 and 17 cells and regulatory $\mathrm{T}$ cells during the development of experimental autoimmune myasthenia gravis. Immunology 2009;128:e826-36.

[37] Wang Z, Wang W, Chen Y, Wei D. T helper type 17 cells expand in patients with myasthenia-associated thymoma. Scand J Immunol 2012;76:54-61. 


\section{Figure legends}

Fig. 1. Representative dot plots for flow cytometric analysis of Tregs (A) and Th17 cells (B).

A: (a) Typical forward and side scatter gates for lymphocytes together with $\mathrm{CD}^{+}$cells were set to exclude contaminating monocytes from the analysis. $\mathrm{CD}^{+}$cells were gated as shown by the squared area. (b) A representative flow cytometric plot of Tregs with FOXP3 and CD25 expression in CD4 ${ }^{+}$ $\mathrm{T}$ cells (upper right quadrant, $\mathrm{CD} 4^{+} \mathrm{CD} 25^{+} \mathrm{FOXP} 3^{+}$). (c) The corresponding isotype control (mouse IgG1). All cells were gated on the $\mathrm{CD}^{+} \mathrm{T}$ population.

B: (d) Lymphocytes were gated as shown by the circled area (R1). (e) The percentage of IL-17A based on intracellular cytokine-positive cells was counted by flow cytometry. (f) The corresponding isotype control (mouse IgG1). All cells were gated on lymphocytes.

FSC: forward scatter; SSC: side scatter

Fig. 2. Relationship between age and the percentage of Treg/CD4 ${ }^{+} \mathrm{T}$ cells in control subjects. There was no correlation between these parameters $(\mathrm{R}=0.19, P=0.45)$. The mean value of Treg/CD4 ${ }^{+} \mathrm{T}$ cells in children was $5.0 \pm 0.6 \%$, which was comparable with that of adult healthy donors $(5.1 \pm$ $0.8 \%, \mathrm{n}=16)$.

Fig. 3. Percentage of Treg/CD $4^{+} \mathrm{T}$ cells at each clinical stage.

The percentage of Tregs among peripheral blood $\mathrm{CD}^{+} \mathrm{T}$ cells in the active stage $(3.3 \pm 1.3 \%)$ was significantly lower than those in the remission stage $(4.8 \pm 1.7 \%, P=0.033)$ and in controls $(5.0 \pm$ $0.6 \%, P<0.001)$.

Bars denote mean \pm SD. N.S.: not significant

Fig. 4. Changes in the percentage of Treg/CD4 ${ }^{+} \mathrm{T}$ cells according to clinical course.

Two representative cases are shown as Case 1 (a) and Case 2 (b). A representative flow cytometric plot of FOXP3 expression on CD4+CD25+T cells gated on the CD4+T population at three different clinical stages are indicated at the bottom of (b).

Solid lines indicate the percentage of Treg/CD4 ${ }^{+} \mathrm{T}$ cells. Dashed lines indicate serum level of anti-AChR antibody.

The changes in the percentage of Tregs before and after relapse in 6 cases are shown in (c). The percentage was markedly lower during relapse in most patients $(P=0.003)$, but returned to initial levels during remission after more intensive treatment $(P=0.009)$.

The shaded area indicates the range obtained from age-matched control subjects $(5.0 \pm 0.6 \%)$.

Fig. 5. Percentage of Th17/CD $4^{+}$T cells in patients and control subjects.

There were no significant differences between the active or remission stage and controls.

Bars denote mean $\pm \mathrm{SD}$. 
Table 1. Patient characteristics and clinical data of test groups and age-matched controls

\begin{tabular}{lccc} 
& \multicolumn{2}{c}{ Patients } & Controls \\
\cline { 2 - 3 } $\mathrm{n}$ & Active & Remission & 18 \\
Age (years) & 12 & 11 & $8.1 \pm 5.0$ \\
$\mathrm{M} / \mathrm{F}$ & $7.8 \pm 4.2$ & $8.8 \pm 4.5$ & $10 / 8$ \\
Oral anti-ChE & $7 / 5$ & $3 / 8$ & - \\
IS treatment & 6 & 8 & - \\
PSL & & & - \\
PSL+Tac & 4 & 5 & - \\
PSL+AZA & 2 & 2 & - \\
None & 0 & 1 & - \\
Thymoma/thymectomy & 6 & 0 & $7808 \pm 2185$ \\
WBC $(/ \mu l)$ & $7290 \pm 2553$ & $7781 \pm 1847$ & $3347 \pm 1193$ \\
Lym $(/ \mu l)$ & $3752 \pm 5572$ & $2410 \pm 1145$ & $2946 \pm 1092$ \\
CD4 $(/ \mu 1)$ & $1487 \pm 1883 *$ & $1000 \pm 188 *$ & \\
Anti-AChR antibody & $1.0 \pm 0.7$ & $0.8 \pm 0.8$ & \\
(nmol/L) & & & \\
\hline
\end{tabular}

anti-AChR antibody: serum anti-acetylcholine receptor antibody; anti-ChE: anti-cholinesterase agent; AZA: azathioprine; CD4: cluster of differentiation 4; CyA: cyclosporine A; F: female; IS: immune suppressant; Lym: lymphocytes; M: male; n: number of samples or control subjects; PSL: prednisolone; Tac: tacrolimus; WBC: white blood cell count; $* P<0.01$ 
A

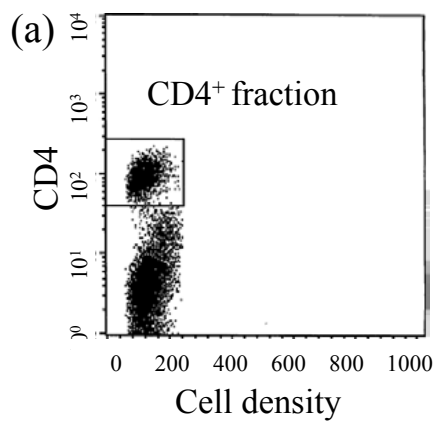

B

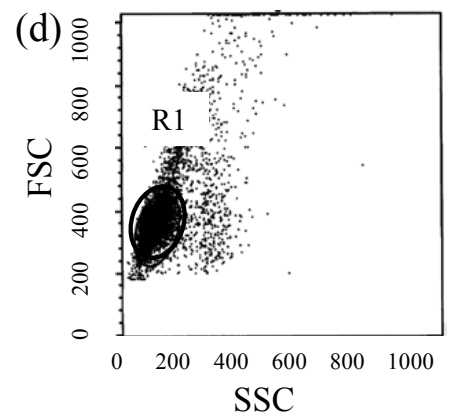

R1 : Lymphocytes
Treg

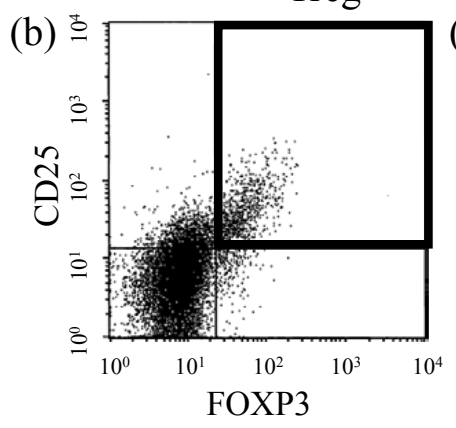

Th17

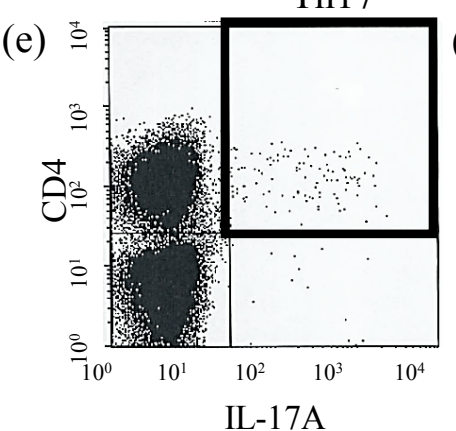

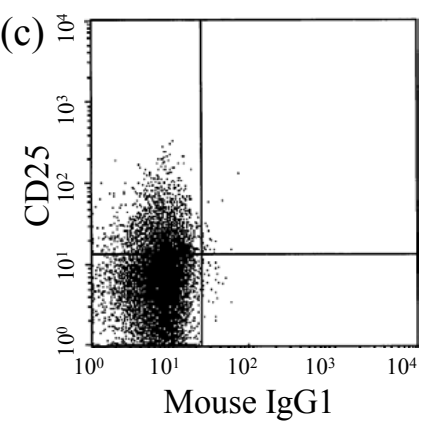

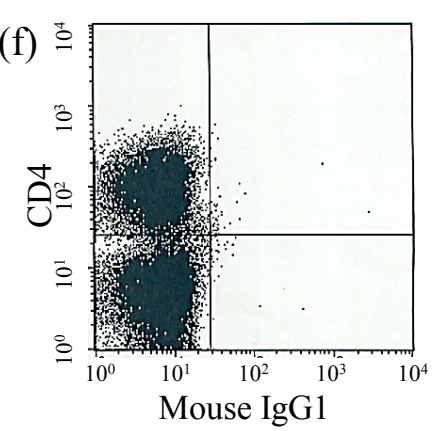


Fig. 2.




Fig. 3.




Fig. 4a.




Fig. 4b.

\section{PSL $0.23 \mathrm{mg} / \mathrm{kg} / \mathrm{day} \quad 0.18 \mathrm{mg} / \mathrm{kg} / \mathrm{day} \quad 0.5 \mathrm{mg} / \mathrm{kg} / \mathrm{day}$}

Distigmine $0.15 \mathrm{mg} / \mathrm{kg}$

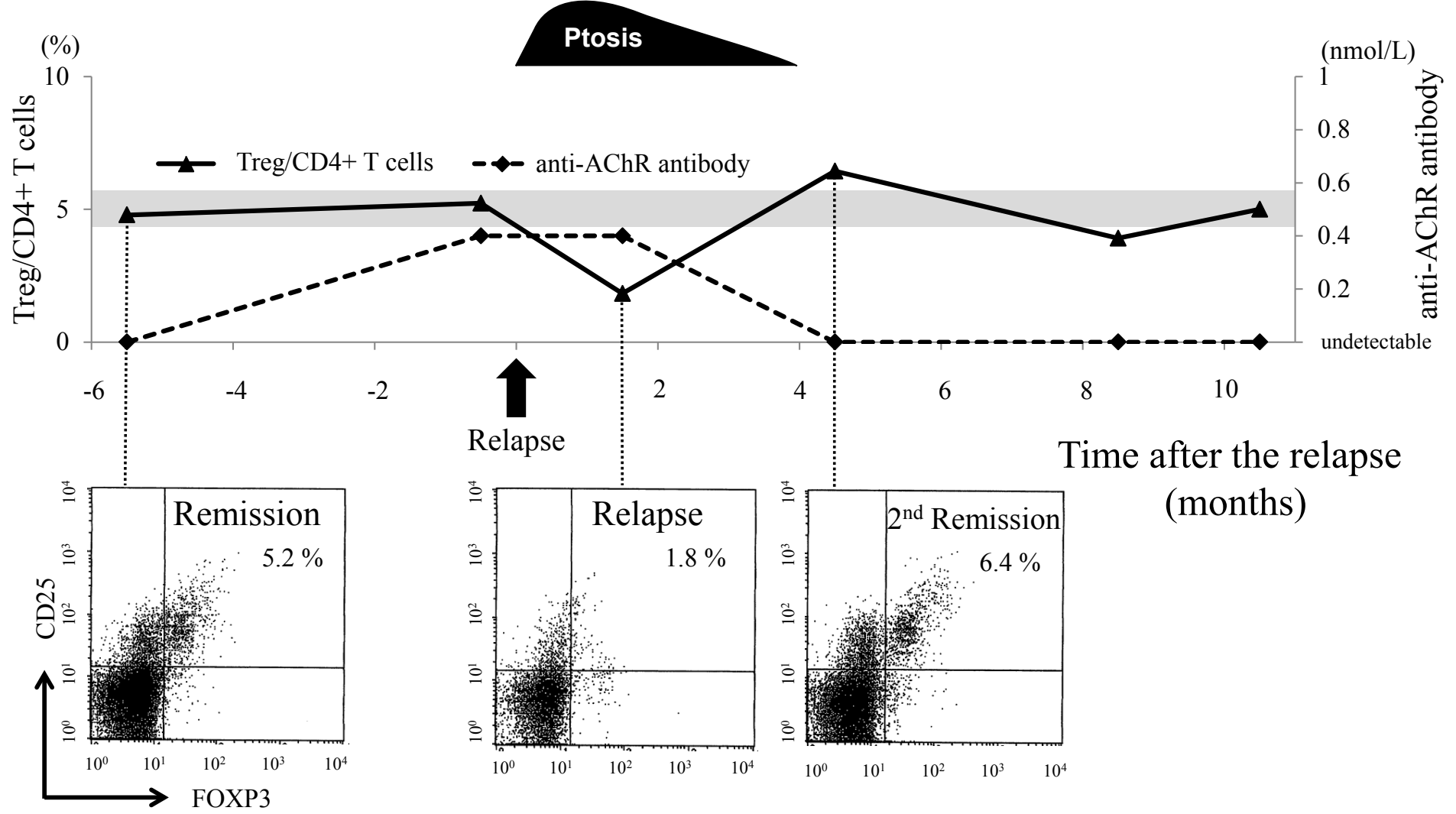


Fig. 4c.

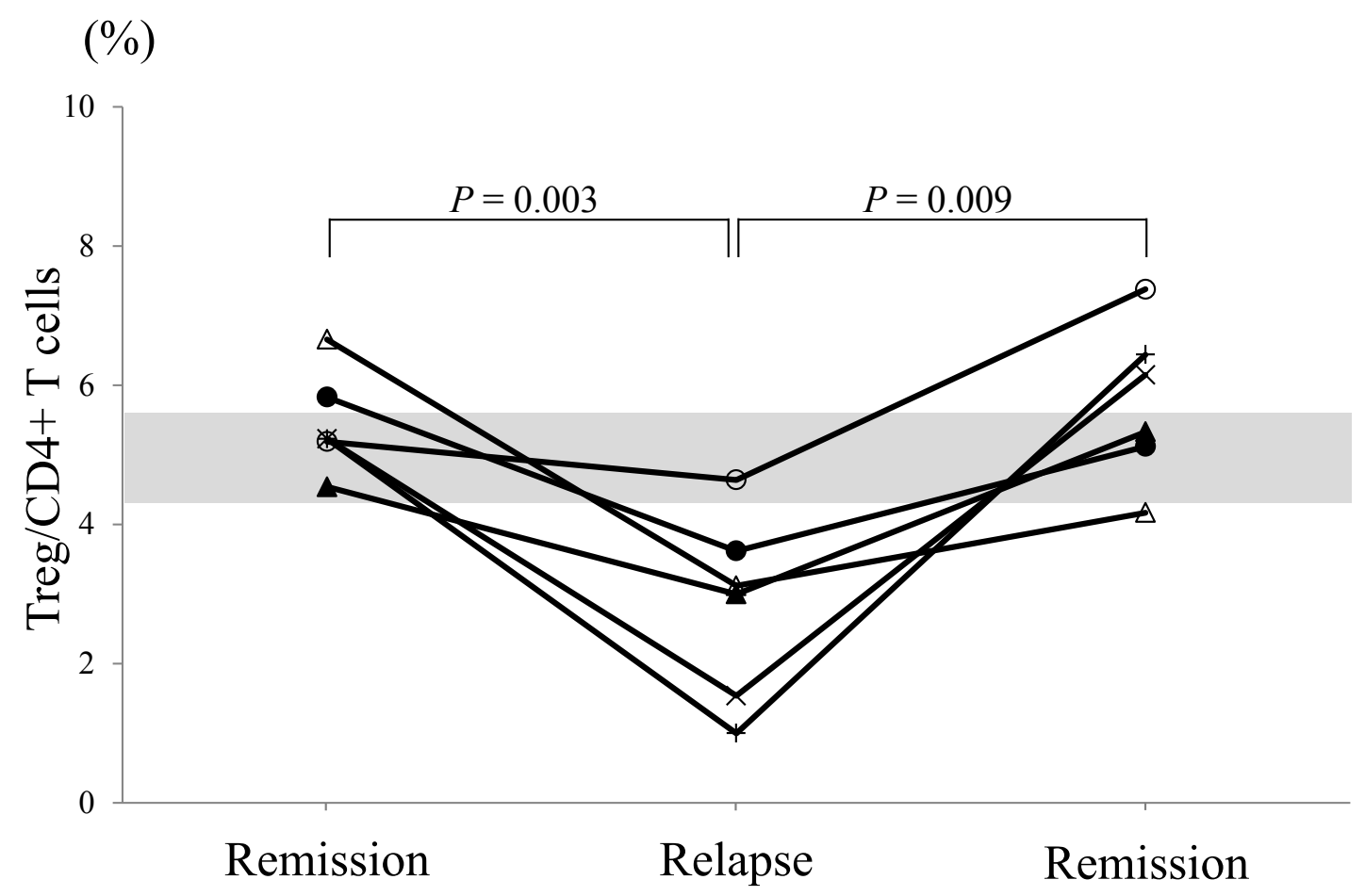


Fig. 5.

(\%)

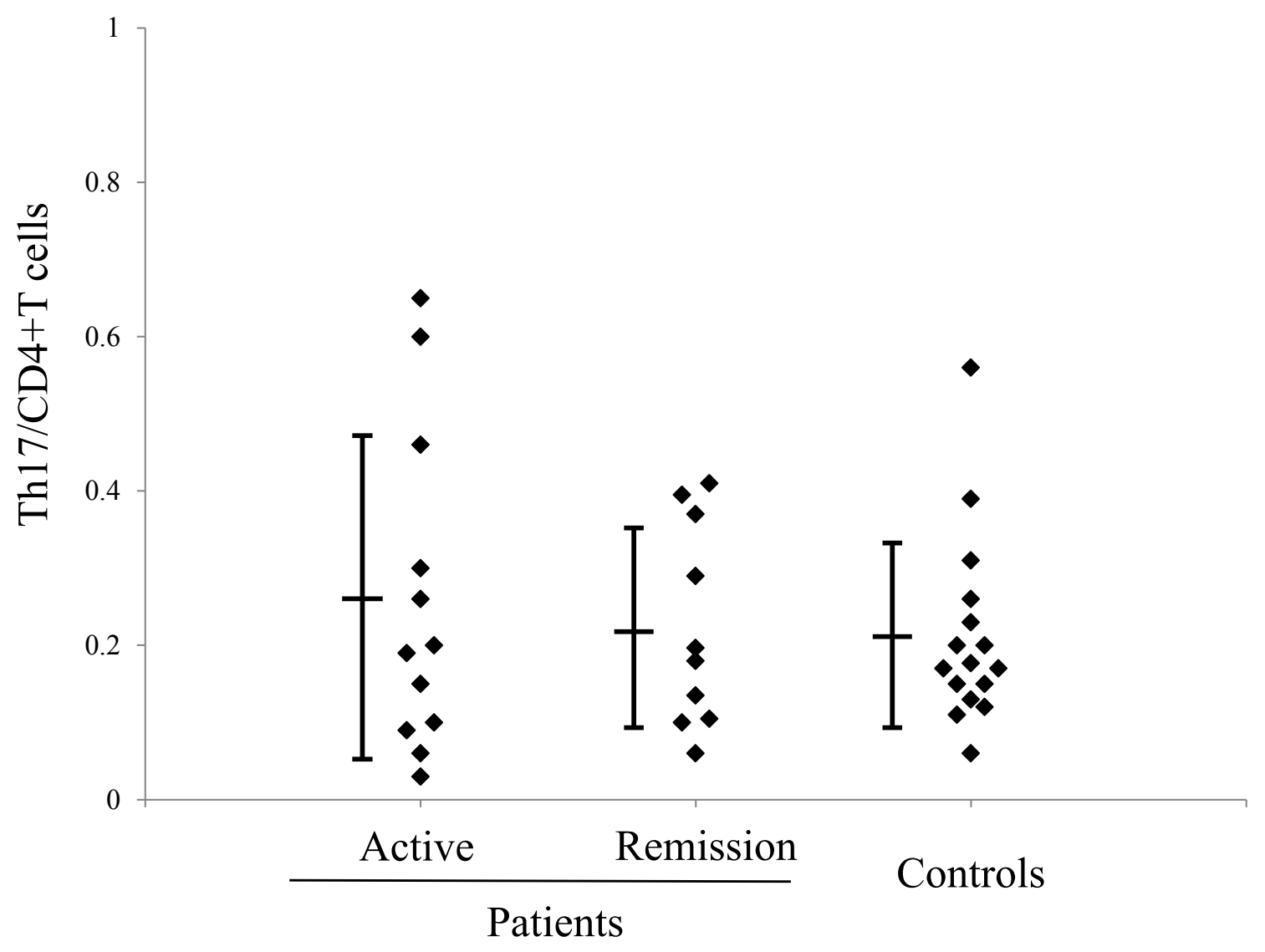

